\title{
The JMA Nonhydrostatic Model and Its Applications to Operation and Research
}

\author{
Kazuo Saito \\ Meteorological Research Institute \\ Japan
}

\section{Introduction}

Nonhydrostatic models were initially developed as research tools for small scale meteorological phenomena. Today, several nonhydrostatic models have been developed and applied to numerical simulations and operational numerical weather prediction (NWP). In this chapter, we review the Japan Meteorological Agency (JMA) nonhydrostatic model (JMA-NHM, hereafter referred to as NHM) and its applications to operational forecasts and research fields. Section 2 presents a brief history of the model development from a research tool to a full-scale NWP model. In section 3, we review applications of the model to several research fields of various time/spatial scales from tornado to regional climate modelling, and mesoscale data assimilation and ensemble prediction studies. Section 4 introduces ongoing relevant topics including the Japanese next generation supercomputer project.

\section{The JMA nonhydrostatic model}

\subsection{Development of NHM at MRI}

The JMA nonhydrostatic model (NHM) was first developed as a research tool at the Meteorological Research Institute (MRI). Ikawa (1988) developed a nonhydrostatic model with orography and compared computational schemes with a 2-dimensional numerical experiment. Following Gal-Chen and Somerville (1975), the terrain-following vertical coordinates

$$
z^{*}=\frac{H\left(z-z_{s}\right)}{H-z_{s}}
$$

and the metric tensors for the coordinate transformations were employed:

$$
G^{\frac{1}{2}}=1-\frac{z_{s}}{H}, \quad G^{\frac{1}{2}} G^{13}=\left(\frac{z^{*}}{H}-1\right) \frac{\partial z_{s}}{\partial x}, \quad G^{\frac{1}{2}} G^{23}=\left(\frac{z^{*}}{H}-1\right) \frac{\partial z_{s}}{\partial y},
$$

where $z_{s}$ is the surface height and $H$ is the model top height.

\subsubsection{Anelastic equation model}

The first version of NHM used the anelastic (AE) scheme to solve the Navier-Stokes momentum equations for a fluid. The AE model removes sound waves from solutions in the 
equation system by scale analysis (Ogura and Phillips, 1962). Field variables are divided into the time independent horizontal uniform reference state $\phi(z)$ and its perturbation $\phi^{\prime}(x, y, z, t)$ as

$$
p=\bar{p}+p^{\prime}, \quad \rho=\bar{\rho}+\rho^{\prime}, \quad \theta=\bar{\theta}+\theta^{\prime} .
$$

Following Clark (1977), the continuity equation was given by

$$
D I V T=\frac{\partial U}{\partial x}+\frac{\partial V}{\partial y}+\frac{\partial W^{*}}{\partial z^{*}}=0,
$$

where $U, V$, and $W$ are momentum multiplied by the metric tensor as the prognostic variables in the model:

$$
\begin{aligned}
& U=\bar{\rho} G^{\frac{1}{2}} u, \quad V=\bar{\rho} G^{\frac{1}{2}} v, \quad W=\bar{\rho} G^{\frac{1}{2}} w, \\
& W^{*}=\frac{1}{G^{\frac{1}{2}}}\left(W+G^{\frac{1}{2}} G^{13} U+G^{\frac{1}{2}} G^{23} V\right) .
\end{aligned}
$$

Taking the total divergence of the momentum equation yields a 3-dimensional Poisson-type pressure diagnostic equation, which was solved by the Dimension Reduction Method.

This model was further evolved by including a bulk cloud microphysics scheme based on Lin et al. (1983), a turbulent closure model based on Deardorff (1980), and treatment surface processes for sea and land. Comprehensive documentation was published in the Technical Report of MRI (Ikawa and Saito, 1991) as a nonhydrostatic model developed at the Forecast Research Department of MRI.

\subsubsection{Nested model}

Ikawa and Saito's (1991) model was modified to a nested model (MRI-NHM) to realistically simulate mesoscale phenomena (Saito, 1994). For the dynamical core, the AE scheme was adopted. Variational calculus (Sherman, 1978) was implemented to obtain a non-divergent mass consistent initial field, where the continuity equation (4) was used as the strong constraint to modify the interpolated wind field. Orlanski's (1976) radiation condition was employed with the time-dependent lateral boundary condition, and mass fluxes through the lateral boundaries were adjusted to maintain mass conservation.

A hydrostatic version of MRI-NHM was developed by Kato and Saito (1995) and was used to examine the applicability of hydrostatic approximation to a high-resolution simulation of moist convection.

\subsubsection{Fully compressible version with a map factor}

Saito (1997) developed a semi-implicit, fully compressible version of MRI-NHM including a map factor, where linearization using the reference atmosphere was removed. Density was defined by the sum of masses of moist air and the water substances per unit volume as 


$$
\rho \equiv \rho_{d}+\rho_{v}+\rho_{c}+\rho_{r}+\rho_{i}+\rho_{s}+\rho_{g},
$$

where subscripts $c, r, i, s$ and $g$ stand for the cloud water, rain, cloud ice, snow, and graupel, respectively. $\rho_{d}$ is the density of dry air and $\rho_{v}$ that of water vapor.

Introducing a map factor $m$, the continuity equation is given by

$$
G^{\frac{1}{2}} \frac{\partial \rho}{\partial t}+D I V T=P R C
$$

where DIVT is the total divergence in $\mathrm{z}^{*}$ coordinate and $U, V$, and $W^{*}$ are defined by

$$
\begin{gathered}
D I V T=m^{2}\left(\frac{\partial U}{\partial x}+\frac{\partial V}{\partial y}\right)+m \frac{\partial W^{*}}{\partial z^{*}}, \\
U=\frac{\rho G^{\frac{1}{2}} u}{m}, \quad V=\frac{\rho G^{\frac{1}{2}} v}{m}, \quad W=\frac{\rho G^{\frac{1}{2}} w}{m}, \\
W^{*}=\frac{1}{G^{\frac{1}{2}}}\left\{W+m\left(G^{\frac{1}{2}} G^{13} U+G^{\frac{1}{2}} G^{23} V\right)\right\} .
\end{gathered}
$$

$P R C$ in (8) is the fall-out of water substances written in $z^{*}$ coordinate:

$$
P R C=\frac{\partial}{\partial z^{*}}\left(\rho_{a} V_{r} q_{r}+\rho_{a} V_{s} q_{s}+\rho_{a} V_{g} q_{g}\right)
$$

where $\rho_{a}$ is the density of moist air, and $V r, V s$ and $V g$ the terminal velocity of precipitable water substances (rain, snow and graupel, respectively). The state equation is given as the diagnostic equation for density:

$$
\rho=\frac{p_{0}}{R \theta_{m}}\left(\frac{p}{p_{0}}\right)^{C_{v} / C_{p}}
$$

where $\theta_{m}$ is the mass-virtual potential temperature defined by

$$
\theta_{m}=\theta\left(1+0.608 q_{v}\right)\left(1-q_{c}-q_{r}-q_{i}-q_{s}-q_{g}\right)
$$

In the AE model, the buoyancy term was computed from the perturbations of potential temperature and pressure, but in the fully compressible model, it is directly computed from the density perturbation.

The pressure equation is obtained from (8) and (13) as

$$
\frac{\partial P}{\partial t}=C_{m}^{2}(P F T-D I V T+P R C)
$$

where $C_{m}$ is the sound wave speed and PFT is the local time tendency of the mass-virtual potential temperature. 
To stabilize the acoustic mode, the HI-VI (Horizontally Implicit-Vertically Implicit) scheme, which treats sound waves implicitly for both vertical and horizontal directions, was used. This scheme, often referred as the semi-implicit method, was first implemented by Tapp and White (1976). A 3-dimensional Helmholtz pressure equation, which is formally similar to the Poisson equation in the AE model, is obtained by HI-VI treatment of sound waves. For details, see Saito (1997) and Saito et al. (2007).

\subsubsection{MRI/NPD-NHM}

In 1999, a cooperative effort to develop a community model for NWP and research started between the Numerical Prediction Division (NPD) of JMA and MRI. The HE-VI (Horizontally Explicit-Vertically Implicit) scheme, which solves a vertically 1-dimensional Helmholtz-type pressure equation, was re-implemented into MRI-NHM by Muroi et al. (2000). Code parallelization of the model was also performed to cope with the distributed memory parallel computers. A flux limiter advection correction scheme (Kato, 1998) was implemented to reduce numerical errors due to the finite difference approximation and to assure monotonicity. In the cloud physics, the box Lagrangian scheme (Kato 1995) was introduced to assure computational stability for sedimentation of rain.

A comprehensive description of the unified model (MRI/NPD-NHM) was published in the Technical Report of MRI (Saito et al., 2001a).

\subsection{Operational applications}

\subsubsection{Development at NPD/JMA}

In 2001, full-scale development of an operational nonhydrostatic mesoscale model at JMA (NHM) was started at NPD in collaboration with MRI. Several modifications were added to enhance computational efficiency, robustness, and accuracy for an operational NWP model.

Higher-order (third to fifth) advection schemes that consider a staggered grid configuration were implemented by Fujita (2003). The fourth-order scheme was chosen for the operational forecasting, considering computational cost and matching with the advection correction scheme. A time-splitting scheme of gravity waves and advection terms was implemented by Saito (2003). In this scheme, higher-order advection terms with advection correction were fully evaluated at the center of the leapfrog time step; the lower-order (second-order) components at each short time step were then adjusted in the latter half of the leapfrog time integration. In the continuity equation, the diffusion of water vapor in unit time, which includes sub-grid scale turbulent mixing and computational diffusion, was considered by Saito (2004) as

$$
G^{\frac{1}{2}} \frac{\partial \rho}{\partial t}+D I V T=P R C+\rho D I F q_{v}
$$

This term was implemented to consider the surface evaporation of water vapor, which offsets the loss of mass by precipitation in total mass conservation.

As for physical processes, the Kain-Fritsch convective parameterization scheme (K-F scheme; Kain and Fritsch, 1993) was implemented with modification by Yamada (2003). 
Several points in the K-F scheme were revised to improve its performance as a mesoscale NWP model in Japan, where a moist and unstable maritime air mass prevails in summer. The targeted moisture diffusion (TMD) was implemented to attenuate the grid-point storms and the associated intense grid-scale precipitation (Saito and Ishida, 2005), where an artificial second-order horizontal diffusion is applied to water vapor when strong upward motions exist.

\subsubsection{Operational MSM}

On 1 September 2004, JMA replaced the former hydrostatic mesoscale model (hydrostatic MSM) with NHM (a nonhydrostatic MSM). Eighteen-hour forecasts were run four times a day to support disaster prevention and the very short-range forecast of precipitation at JMA. A domain of $3600 \mathrm{~km} \times 2880 \mathrm{~km}$ that covers Japan and its surrounding areas was taken. Vertically, 40 levels with variable grid intervals were employed, where the model top was located at $22 \mathrm{~km}$ and the lowest level was $20 \mathrm{~m}$.

Initial conditions of horizontal wind, temperature, water vapor, and surface pressure were given by the JMA Meso 4D-Var (Koizumi et al., 2005) six-hourly analyses, as in the former hydrostatic MSM. Initial conditions of cloud microphysical quantities were given by the sixhourly forecast-forecast cycle. Details of the $10 \mathrm{~km}$ nonhydrostatic MSM are given in Saito et al. (2006).

\subsubsection{Upgrade of MSM after 2006}

In March 2006, horizontal and vertical resolutions of the nonhydrostatic MSM were enhanced from $10 \mathrm{~km}$ L40 to $5 \mathrm{~km}$ L50. The model operation was also increased from four times a day (six hourly) to eight times (three hourly), to provide more frequent forecasts. Several modifications were added to physical processes. In the atmospheric radiation scheme of the 10 km MSM, a cloud was assumed as a black body and cloud optical properties were given by empirical constants. In the new radiation scheme, cloud optical properties were determined by cloud water/ice contents and their effective radius, which reduced the negative bias of the upper air temperature. Convective parameterization was still required at $5 \mathrm{~km}$, because without convective parameterization the model overestimated intense rain and underestimated weak to moderate rains. In the K-F scheme, the following revisions were made (Ohmori and Yamada 2006): (1) conversion from convective condensate to rain was reduced, (2) time scales of deep and shallow convection were reduced, and (3) threshold values for conversion from cloud water/ice to precipitation were increased.

In May 2007, JMA extended the forecast time of MSM from 15 to 33 hours at the initial times of $03,09,15$ and 21 UTC to provide information for disaster prevention up to 24 hours (Hara et al., 2007). To modify the dynamics, the generalized hybrid vertical coordinate,

$$
\zeta=z-z_{s} f(\zeta)
$$

was introduced, which approaches the $z^{*}$ coordinate near the surface and the $z$ coordinate near the model top (Ishida, 2007). Here, $f(0)=1, f(H)=0$, and $f(\zeta)$ is determined so that $\partial z / \partial \zeta$ is positive and the second derivative of $f(\zeta)$ is differentiable. In the cloud microphysics, fallout of cloud ice was considered in addition to rain, snow, and graupel in order to prevent excessive accumulation of cloud ice in the upper model atmosphere. In the K-F scheme for 
convection, perturbation depending on relative humidity was added in the trigger function to reduce the overestimation of convective rain induced by orography. For the turbulent model, a Mellor and Yamada level-3 closure model (MYNN3; Nakanishi and Niino, 2004; 2006) was implemented first as the operational NWP model to reduce model bias in the boundary layer (Hara, 2007). In addition to the prognostic turbulent kinetic energy (TKE), fluctuations of liquid water potential temperature $\left(\theta_{l}^{\prime}\right)$, total water content $\left(q_{w}{ }^{2}\right)$, and their correlation $\left(\theta_{l}^{\prime} q_{w}{ }^{\prime}\right)$ were treated as prognostic variables. To evaluate the degree of cloudiness, partial condensation computed by the probability density function in MYNN3 was considered. Results of these modifications are given in Saito et al. (2007)

A nonhydrostatic 4D-Var data assimilation system (JNoVA; JMA Nonhydrostatic model based Variational data assimilation system) (Honda et al., 2005) was implemented in April 2009 to supply MSM more accurate initial conditions (Honda and Sawada, 2008). The horizontal resolution of the 4D-Var inner-loop model was enhanced from $20 \mathrm{~km}$ of Meso $4 \mathrm{D}-\mathrm{Var}$ to $15 \mathrm{~km}$ in JNoVA.

\subsubsection{QPF performance of MSM}

Figure 1 plots the quantitative precipitation forecast (QPF) performance of MSM since it began actual operation (March 2001) to November 2011. In this figure, threat scores averaged for $\mathrm{FT}=3$ to 15 for moderate rain with a threshold value of $5 \mathrm{~mm}$ in 3 hours are indicated. The verification grid size is $20 \mathrm{~km}$. The averaged score in 2001 was about 0.2 , but the score improved year by year, and the latest score approaches 0.4. Given the fact that statistical PQF performance of high resolution regional models is sometimes notoriously bad due to the difficulty of predicting mesoscale precipitation and the double penalty problem, this threat score improvement is remarkable.

Table 1 lists the main modifications added to the operational mesoscale NWP at JMA from 2001 to 2011. In addition to the modifications discussed in the former subsections, the global positioning system (GPS)-derived total precipitable water vapor (TPWV) data (Ishikawa, 2010) has been assimilated since October 2009, and the 1D-Var retrieved water vapor data from radar reflectivity (Ikuta and Honda, 2011) has been used since June 2011. These modifications have contributed to the recent improvement of the QPF performance of MSM through improving water vapor analysis.

\subsubsection{Mesoscale tracer transport model}

The GPV of the operational MSM is used as input to the atmospheric transport model at MRI and JMA. This mesoscale ATM takes a Lagrangian scheme (Seino et al., 2004) with many tracer particles that follow advection, horizontal and vertical diffusion, fallout, and dry and wet deposition processes. JMA incorporated photochemical oxidant information in June 2007 (Takano et al., 2007) and the tephra fall forecast in March 2008 (Shimbori et al., 2010).

\section{Applications to research}

\subsection{Mountain flow}

As described in section 2.1, NHM was first developed as a research tool at MRI. Ikawa and Nagasawa (1989) conducted a numerical experiment for a dynamically induced foehn event 


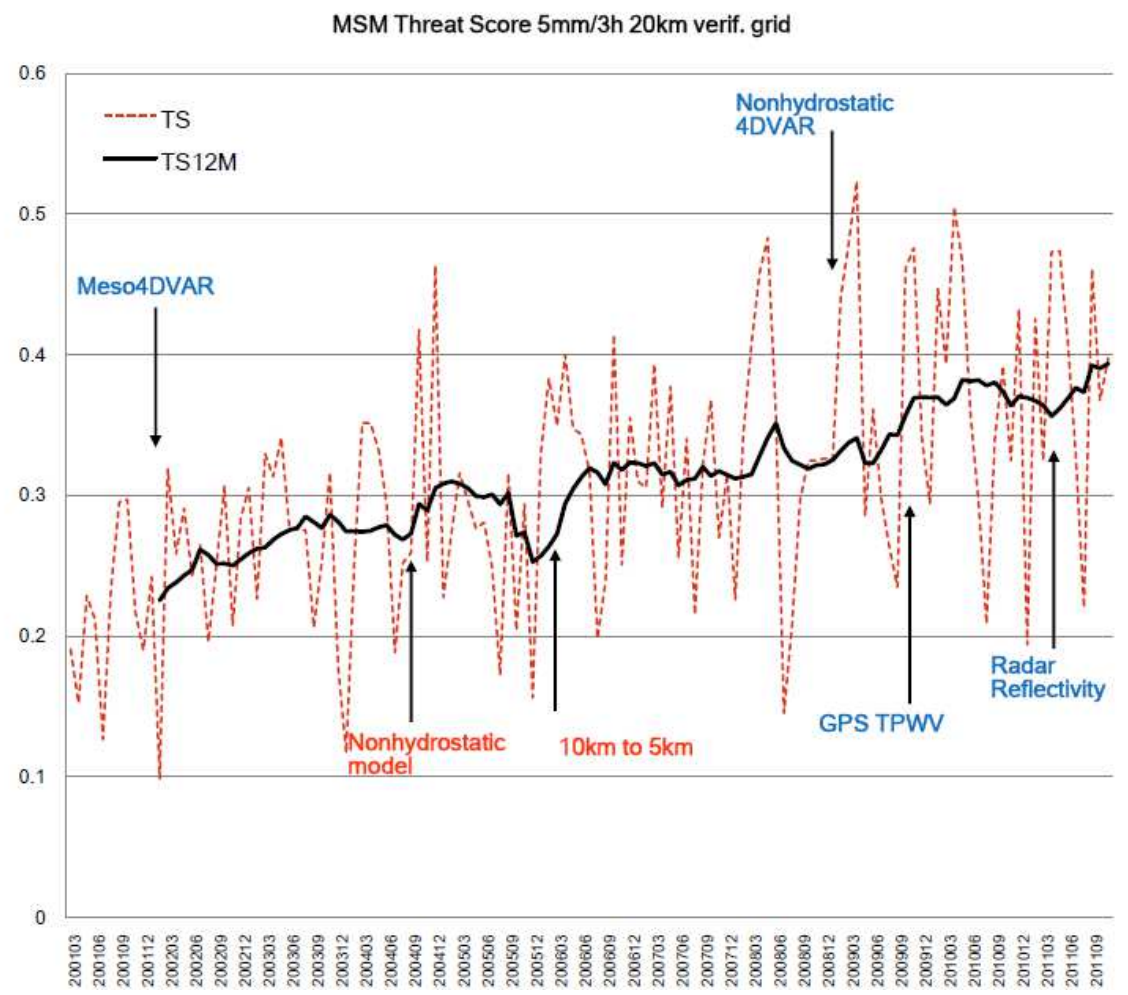

Fig. 1. Threat score of MSM for three-hour precipitation averaged for FT $=3$ to 15 with a threshold value of $5 \mathrm{~mm} / 3$ hour from March 2001 to November 2011. The red broken line denotes the monthly value, while the black solid line indicates the 12-month running mean. Courtesy of NPD/JMA.

\begin{tabular}{|c|l}
\hline Year. Month & \multicolumn{1}{c}{ Modification } \\
\hline 2001.3 & Start of Mesoscale NWP (10kmL40+OI) \\
\hline 2001.6 & Wind profiler data \\
\hline 2002.3 & Meso 4D-Var \\
\hline 2003.10 & SSM/I microwave radiometer data \\
\hline 2004.7 & QuikSCAT Seawinds data \\
\hline 2004.9 & Nonhydrostatic model \\
\hline 2005.3 & Doppler radar radial winds data \\
\hline 2006.3 & Enhancement of model resolution (5kmL50) \\
\hline 2007.5 & Upgrade of physical processes \\
\hline 2009.4 & Nonhydrostatic 4D-Var \\
\hline 2009.10 & GPS total precipitable water vapor (TPWV) data \\
\hline 2011.6 & Water vapor data retirieved from radar reflectivity \\
\hline
\end{tabular}

Table 1. Modifications for operational mesoscale NWP at JMA. 
observed in Hokkaido, northern Japan, using the 2-dimensional AE model. Inspired by their works, Saito and Ikawa (1991) conducted 2-dimensional simulation of the local downslope wind Yamaji-kaze in Shikoku, western Japan. The averaged orography of Shikoku Island in the east-west direction was regarded as the typical orography, and the development and propagation of an internal hydraulic jump were simulated by a numerical experiment using the observed thermal stratification and time-changing wind profile.

Saito (1993) conducted numerical experiments using the real orography of Shikoku Island with the surface friction, and studied the geographical characteristics of the Yamaji-kaze. Smith's (1980) linear analytic solution of the mountain flow over an isolated mountain was extended to the flow over a mountain range with a col, and compared with the non-linear aspect of the simulated flow.

Saito (1994) developed a double-nested model to reproduce the Yamaji-kaze of the 27 September 1991 windstorm. A realistic simulation of the observed phenomena was first conducted in Japan using a nested nonhydrostatic model with a horizontal resolution of 2.5 $\mathrm{km}$. Good agreement between the simulation and the observed time evolution of surface wind was obtained when a strong typhoon approached western Japan.

The Kii Peninsula, central Japan, is famous for its abundant rainfall which reaches 3000 to $4000 \mathrm{~mm}$ a year. Airflow over the Kii Peninsula and its relation to the orographic enhancement of rainfall has been studied by Saito et al. (1994) and Murata (2009). Saito et al. (1998) compared the Deutscher Wetterdienst nonhydrostatic regional model (DWD LM) and MRI-NHM for numerical solutions of the 3-dimensional mountain waves, focusing on the computational efficiency of HI-VI and HE-VI schemes. Fujibe et al. (1999) studied diurnal wind variation in the lee of a mountain range using MRI-NHM and demonstrated agreement with the daytime advance of downslope wind in the Canterbury Plains in New Zealand.

A model intercomparison of mountain flow over a steep mountain was conducted by Satomura et al. (2003) as the Steep Mountain Model Intercomparison Project (St-MIP). To examine the accuracy of the terrain-following coordinates, mountain waves over twodimensional bell-shaped mountains with various half-widths and heights were compared with theoretical calculations and among models, including NHM.

\subsection{Tropical meteorology}

\subsubsection{Tropical convection and heavy rainfall}

A model intercomparison for a tropical squall line observed during the Ttropical Ocean/Global Atmosphere Coupled Ocean-Atmosphere Response Experiment (TOGA COARE) was conducted in the GEWEX Cloud Systems Study (GCSS). Redelsperger et al. (2000) compared results from eight cloud-resolving models including NHM. Most of the models were able to predict similar rainfall and integrated water content evolutions and agreed quantitatively, but the apparent heat and moisture sources indicated some quantitative differences.

The diurnal evolution of tropical island convection observed during the Maritime Continent Thunderstorm Experiment (MCTEX; Keenan et al., 2000) was simulated by Saito et al (2001b) using NHM nested with the Australian Bureau of Meteorology Research Centre's 
Limited-Area Assimilation and Prediction System (BMRC LAPS). The left panel of Fig. 2 presents the visible satellite images over Melville and Bathurst Islands, Northern Territory of Australia, on 27 November 1995. At 1200 CST, shallow convective clouds corresponding to Rayleigh-Benard convection covered the interior of the islands. Along the southern coasts of the two islands, line-shaped clouds suggest organization associated with the sea breeze front (SBF). At 1300 CST, the clouds merged and organized at the central part of the islands in the form of an east-west line. An hour later (1400 CST), deep convection (Hector) developed at the southwestern part of Melville Island and along the southern coast of Bathurst Island. The right panel of Fig. 2 indicates the corresponding simulation with a $1 \mathrm{~km}$ NHM. Details of the observed evolution of the clouds on this day (Rayleigh-Benard convection, cloud merger along the convergence zone between the two SBFs, and succeeding explosive growth of deep convection) were very well reproduced.
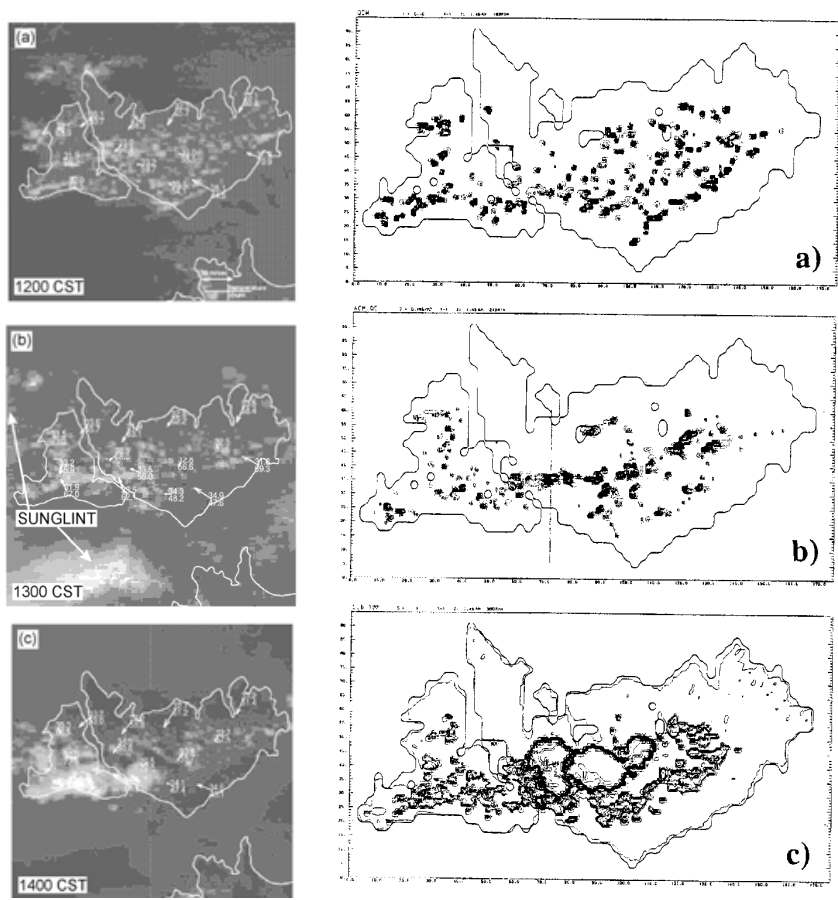

Fig. 2. Left: Visible image on 27 Nov 1995: (a) at 0230 UTC (1200 CST), (b) at 0330 UTC (1300 CST), and (c) at 0430 UTC (1400 CST). Right: Fields derived from the $1 \mathrm{~km}$ NHM simulation. (a) Cloud water mixing ratio at $z=1.46 \mathrm{~km}$ and $t=180 \mathrm{~min}$ (1300 CST). Contour interval is $0.1 \mathrm{~g} \mathrm{Kg}^{-1}$. (b) Vertically accumulated cloud water at $t=240 \mathrm{~min}$ (1400 CST). Contour interval is $0.1 \mathrm{Kg} \mathrm{m}^{-2}$. (c) Simulated cloudtop temperature at $t=300 \mathrm{~min}$ (1500 CST). Contour interval is $5 \mathrm{~K}$. After Saito et al. (2001b).

On 26 July 2005, an intense rainfall system caused heavy rain in excess of $900 \mathrm{~mm}$ at Mumbai, on the west coast of India. This system was simulated by Seko et al. (2008) using the global analysis data of JMA as the initial condition of NHM. A maximum rainfall exceeding $1,100 \mathrm{~mm}$ in 17 hours was reproduced by the simulation with a horizontal 
resolution of $5 \mathrm{~km}$. The detailed structure of the rainfall system at the intense rain stage was also investigated by NHM with a horizontal resolution of $1 \mathrm{~km}$ and sensitivity experiments.

A flood was caused by heavy rainfall that lasted for several days from late January to early February 2007 in Jakarta and its vicinity. Trilaksono et al. (2012) investigated spatiotemporal modulation of precipitation using time-lagged ensemble. The National Centers for Environmental Prediction (NCEP) Global Analyses with a horizontal resolution of $1^{\circ} \times 1^{\circ}$ was used for the initial and boundary conditions of NHM with a horizontal resolution of 20 $\mathrm{km}$. They demonstrated that the event associated with a cold surge was preceded by a Borneo vortex event. Trilaksono et al. (2011) conducted downscaling experiments for the Jakarta Flood, and studied the dependence of heavy precipitation simulated by the model on the horizontal resolution. The downscale runs with higher resolutions $(2,4$, and $5 \mathrm{~km})$ demonstrated the ability to reproduce a region of strong convective activity to the north of Java Island during the flood.

Seko et al. (2012) investigated generation mechanisms of convection cells in tropical regions. Convection cells near Sumatra Island were reproduced using the reanalysis data of the JMA Climate Data Assimilation System (JCDAS) and downscale experiments with a horizontal grid interval of $1 \mathrm{~km}$. Updrafts of gravity waves that were trapped in the lower atmosphere triggered new convection cells.

\subsubsection{Tropical cyclone and tornado}

Murata et al. (2003) was the first to apply MRI-NHM to a typhoon. They numerically simulated the major spiral rainband in typhoon Flo (T9019), which was the subject of an international model intercomparison (COMPARE III; Nagata et al., 2001), with several horizontal resolutions $(20,14,10,7$ and $5 \mathrm{~km}$ ). The effects of precipitation schemes and horizontal resolution on the representation of the simulated rainband were studied.

Effects of ice-phase processes and evaporation from raindrops on the development and structures of tropical cyclones were studied by Sawada and Iwasaki (2007; 2010). Wada (2009; 2012) and Wada et al. (2010) used an atmosphere-wave-ocean coupled version of NHM to examine the effect of the ocean on tropical-cyclone intensity and structural change. Wong et al. (2010) developed a new parameterization scheme of air-sea momentum, heat, and moisture fluxes, considering the saturation properties of bulk transfer coefficients under a high winds regime, and tested its impact on tropical cyclone intensity. Kanada et al. (2012) compared PBL schemes and examined their impact on the development of intense tropical cyclones.

In May 2008, Cyclone Nargis hit southern Myanmar and claimed more than 100,000 lives there in one of the largest meteorological disasters in Southeast Asia, mainly due to the storm surge. Numerical modeling studies of this event were performed as part of the research project "International Research for Prevention and Mitigation of Meteorological Disasters in Southeast Asia" (see 3.2.3). Kuroda et al. (2010) conducted a forecast experiment of Nargis and its associated storm surge using NHM with a horizontal resolution of $10 \mathrm{~km}$ and the Princeton Ocean Model (POM) with a horizontal resolution of $3.5 \mathrm{~km}$. The impact of SST in the Bay of Bengal and ice phase on Nargis' rapid development was also examined. 
The greatest typhoon damage in Japan was caused by 'Isewan Typhoon' (Vera) and its associated storm surge in 1959. Kawabata et al. (2012) performed a reanalysis experiment of the typhoon using JNoVA, assimilating drop sonde observations taken by the US Air Force.

Mashiko et al. (2009) performed a numerical simulation of tornadogenesis in an outerrainband minisupercell of a typhoon using NHM with a grid spacing of $50 \mathrm{~m}$.

\subsubsection{International research for prevention and mitigation of meteorological disasters in Southeast Asia}

In 2007, Kyoto and MRI started the project "International Research for Prevention and Mitigation of Meteorological Disasters in Southeast Asia" (http://www-mete. kugi.kyotou.ac.jp/project/MEXT/) with institutions in southeast Asia. This project was supported for fiscal years 2007 through 2009 by the Asia S \& T Strategic Cooperation Program of the Ministry of Education, Culture, Sports, Science and Technology of Japan (MEXT) Special Coordination Funds for Promoting Science and Technology. Numerical experiments were performed at the Institut Technologi Bandung (ITB) in Indonesia, Hong Kong Observatory, Nanyang Technological University in Singapore, National Center for Hydro-Meteorological Forecasting of Vietnam, and CSIR Centre for Mathematical Modelling and Computer Simulation in India.

MRI was a major participating institution in Japan, and was responsible for NWP model development and application. Case studies with downscale prediction and statistical verifications of forecast accuracy around Japan and Southeast Asia were performed. Hayashi et al. (2008) compared NHM and the Weather Research Forecasting (WRF) model for two seasons (July 2007 and January 2008) with the same initial and boundary conditions and the same domain size and resolutions. Tools were prepared for numerical experimentations with NHM using the JMA global analysis, the global model forecast, and the JMA one-week global ensemble forecast. Saito et al. (2010a) conducted ensemble predictions of Nargis and the associated storm surge employing perturbations from the JMA one-week global ensemble forecast. Ensemble prediction results were used as input data for the decision support system developed by Kyoto University (Otsuka and Yoden, 2011).

Data assimilation experiments were conducted by modifying the JMA Meso 4D-VAR system to apply to tropical areas. A tropical cyclone (TC) bogus procedure was developed for the Bay of Bengal, and the impact on TC forecasts was investigated by Kunii et al. (2010b). Nearreal-time (NRT) analysis of precipitable water vapor using the international ground based GPS network around the Bay of Bengal was performed to demonstrate its positive impact on the Nargis forecast (Shoji et al., 2011).

A comprehensive description of this international project including newsletters, the users' guide to the decision support tool, and links to related published papers has been published as a technical report of MRI (Saito et al., 2011b).

\subsection{Cloud simulations}

\subsubsection{Winter monsoon snow clouds over the Sea of Japan}

Ikawa et al. (1991) implemented a bulk parameterization scheme of cloud microphysics to MRI-NHM, and performed a numerical simulation of the convective snow cloud over the Sea of Japan. Sensitivity experiments to ice nucleation rates were conducted to simulate the 
cloud more realistically and to examine the effects of an increase in the number concentration of ice crystals on the formation of the convective snow cloud.

Saito et al. (1996) conducted sensitivity experiments on the orographic snowfall over the mountainous region of northern Japan, and investigated the orographic effect on the snowfall from cloud microphysical aspects. A 2-dimensional model with a horizontal resolution of $2 \mathrm{~km}$ was employed. In the experiments with full cloud microphysics, the precipitation amount over the land increased significantly with mountain heights exceeding the height of the cloud base. However, in the experiments with a warm-rain process, the precipitation amount was only $1 / 3$ that of the experiments with an ice phase. A seeding experiment in which ice nucleation rates were enhanced over a specified zone in the Sea of Japan demonstrated the possibility of artificial modification of the snowfall. A further seeding experiment was conducted by Hashimoto et al. (2008), and seedability of the winter orographic snow clouds over northern Japan was assessed using a nested NHM with a horizontal resolution of $1 \mathrm{~km}$.

Saito (2001) conducted a numerical simulation of cloud bands during a cold air outbreak over the Sea of Japan with a horizontal resolution of $3 \mathrm{~km}$, and showed outstanding similarity between the satellite image and simulated clouds. Four nodes of the HITAC SR8000 of MRI were employed. A higher resolution $(1 \mathrm{~km})$ simulation of the snow clouds over the southern coastal area of the Japan Sea was conducted by Eito et al. (2005). Eito et al. (2010) extended the simulation area to $(2000 \mathrm{~km})^{2}$ and examined the structure and formation mechanism of transversal cloud bands using the Earth Simulator.

Yanase et al. (2002) conducted high-resolution simulation of an observed polar low over the Japan Sea on 21 January 1997 with the 2-km horizontal resolution MRI-NHM. The simulation successfully reproduced the observed features of the polar low (e.g., its horizontal scale, movement, spiral bands, and a cloud-free eye). Detailed three-dimensional structures of the simulated polar low were clarified, and its development mechanism was investigated. Futher siumulations of the polar low were conducted by Yanase et al. (2004) and Yanase and Niino (2007).

\subsubsection{Maritime boundary layer clouds and spectral bin methods}

Nagasawa et al. (2006) conducted numerical simulation of Yamase clouds, typical maritime boundary-layer clouds over the sea off the east coast of northern Japan. NHM with a high resolution of $100 \mathrm{~m}$ was employed to simulate convective structures observed from satellite images.

Iguchi et al. (2008) implemented a bin-based microphysics scheme for cloud into NHM to reproduce realistic and inhomogeneous condensation nuclei $(\mathrm{CN})$ fields. Nested simulations were performed for two precipitation events over an area of the East China Sea, where the general features of the horizontal distributions of variables (e.g., effective droplet radius derived from satellite data retrieval) were reproduced. Iguchi et al. (2012) evaluated the binbased cloud microphysical scheme through comparison with observation data by shipborne Doppler and spaceborne cloud profiling radars.

\subsection{Regional climate modelling and urban simulation}

A regional climate model version of NHM employing spectral boundary coupling (SBC) was developed by Yasunaga et al. (2005). Forty-day simulations with a horizontal grid 
interval of $5 \mathrm{~km}$ were performed using the Earth Simulator in the MEXT Research Revolution 2002 project. Kanada et al. (2005) used this version of NHM and examined structure of mesoscale convective systems (MCSs) during the late Baiu season in the global warming climate. Sasaki et al. (2008) performed five-year integrations of the non-hydrostatic regional climate model (NHRCM) with a $4 \mathrm{~km}$ grid interval, and successfully reproduced monthly precipitation, seasonal change, and regional features in Japan. The relationship between precipitation and elevation in the present climate by NHRCM was compared with observation by Sasaki and Kurihara (2008). The climatological features of warming events over Toyama Plain, central Japan, were investigated with NHRCM by Ishizaki and Takayabu (2009).

A single-layered square prism urban canopy (SPUC) scheme for NHM was developed by Aoyagi and Seino (2011). The SPUC run more accurately reproduced the expected behavior of the urban canopy effect than the slab run did.

\subsection{Mesoscale data assimilation and ensemble forecast}

As shown in Fig. 1, QPF performance of operational mesoscale NWP at JMA has been remarkably improved in these ten years for weak to moderate rains. However, there are still many difficulties in producing predictions of severe mesoscale phenomena that specify their intensity, location, and timing. Convective rains without strong synoptic or orographic forcing are still very hard to predict due to the smallness of their spatiotemporal scales and their sensitivity to the small perturbations in the initial condition. To overcome these difficulties, research and development on mesoscale data assimilation and ensemble forecast have been conducted.

\subsubsection{Mesoscale assimilation of GPS data}

Water vapor is one of the most important parameters in weather forecasting, and GPS is a powerful tool for retrieving accurate water vapor information. In Japan, the Geospatial Information Authority of Japan has been operating a nationwide permanent dense GPS array, the GPS Earth Observation Network (GEONET), since 1994. Shoji (2009) developed a near real-time (NRT) analysis system of TPWV derived from GEONET data to contribute to water vapor monitoring and NWP. Ishikawa (2010) applied this system to the operational GPS TPWV data assimilation at JMA using JNoVA and contributed to improve the MSM's QPF performance (see 2.2.4).

On 28 July 2008, a local heavy rainfall occurred over the Hokuriku and Kinki districts, central Japan. Shoji et al. (2009) used Meso 4DVAR to perform data assimilation experiments of GEONET TPWV data for this event, and demonstrated that the rainfall forecast was improved. Further improvements were obtained by adding TPWV derived from GPS stations of the International GNSS Service in Korea and China.

Seko et al. (2010) used the Meso 4D-Var system for a heavy rainfall event in northern Japan on 16 July 2004 to investigate the impacts of three kinds of GPS-derived water vapor data: TPWV, slant water vapor along the path from the GPS satellite to the receiver (SWV), and radio occultation (RO) data along the path from the GPS satellite to the CHAllenging Minisatellite Payload (CHAMP) satellite. When SWV and RO data were assimilated simultaneously, both the rainfall region and rainfall amount were similar to the observed ones. 


\subsubsection{Storm scale 4DVAR}

Although JNoVA contributed to improve the QPF performance of operational MSM, its horizontal grid spacing in the inner loop model is $15 \mathrm{~km}$ and only large-scale condensation is considered in the adjoint model. Kawabata et al. (2007) developed a cloud-resolving 4DVAR system based on the JMA-NHM (NHM-4DVAR), and applied it to reproduce the deep convection observed in Tokyo on 21 July 1999. The cost function to be minimized was formulated as

$$
J\left(x_{0}\right)=\frac{1}{2}\left(x_{0}-x_{0}^{b}\right)^{\mathrm{T}} \mathbf{B}^{-1}\left(x_{0}-x_{0}^{b}\right)+\frac{1}{2}\left(H x-y^{o}\right)^{\mathrm{T}} \mathbf{R}^{-1}\left(H x-y^{o}\right),
$$

where $x$ denotes the model prognostic variables, subscript 0 means those at the beginning time of the assimilation window, and $x_{0}{ }^{b}$ is the first guess of $x_{0}$. B represents the background error covariance matrix. $H$ is the observation operator, $y^{o}$ is the observations, and $\mathbf{R}$ the observation error covariance matrix. Lateral boundary conditions were also included in the analysis. The adjoint model included only dry dynamics and advection of water vapor, but they successfully reproduced observed cumulonimbi by assimilating Doppler radar radial winds and GPS TPWV data. This study was the first to demonstrate the feasibility of shortrange forecasting of local heavy rainfall brought about by deep convection, using a full-scale numerical model and a dense observation network.

Kawabata et al. (2011) implemented the warm rain process into NHM-4DVAR and applied it to a data assimilation experiment of a heavy rainfall event in Tokyo on 5 September 2005 with a horizontal resolution of $2 \mathrm{~km}$. GPS-TPWV data was assimilated at 5-min intervals within the 30-min assimilation windows, and surface in-situ data and wind profiler data were assimilated at 10-min intervals. Doppler radial winds and radar-reflectivity data were assimilated at 1-min intervals. The 4DVAR assimilation reproduced a line-shaped mesoscale convective system (MCS) with a shape and intensity consistent with the observation (Fig. 3). Assimilation of radar-reflectivity data intensified the MCS and suppressed false convection.

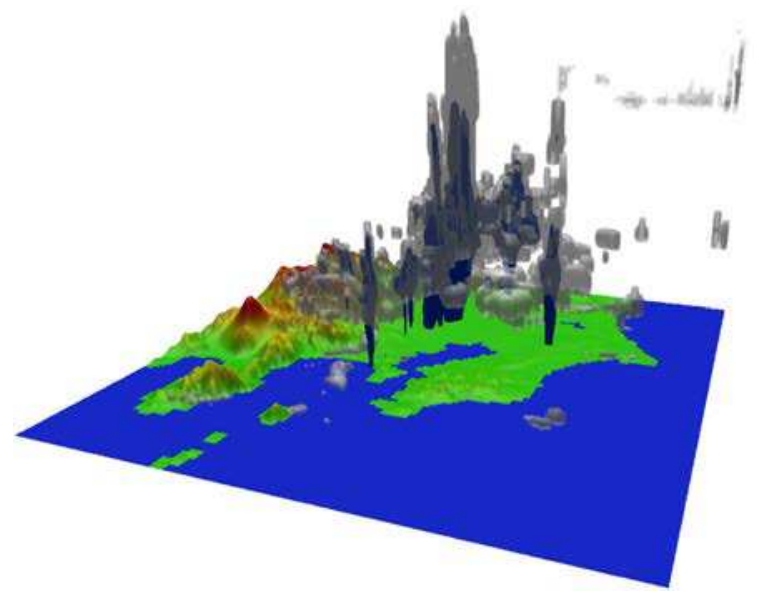

Fig. 3. Three-dimensional image of the MCS in Tokyo on 5 September 2005 reproduced by NHM-4DVAR. 


\subsubsection{Mesoscale ensemble prediction}

Another reason of difficulty in predicting local heavy rainfall is the inherent low predictability of severe small-scale phenomena, that occur under convectively unstable atmospheric conditions. To consider forecast errors due to uncertainties in initial conditions and numerical models, ensemble prediction systems (EPSs) are widely used for medium range NWP, and there is now an increasing need to develop mesoscale EPSs.

Seko et al. (2009) conducted 11-member mesoscale ensemble experiments using NHM with a horizontal resolution of $15 \mathrm{~km}$ for two tornado events in Japan. Initial conditions were produced by adding the normalized perturbation of operational one-week ensemble forecast of JMA. Probabilities that the Energy Helicity Index (EHI) exceeds some criteria were examined, and feasibility of the probability forecast of tornadoes using the EPSderived potential parameters was indicated.

As discussed in 3.2.3, Saito et al. (2010a) conducted ensemble predictions of Nargis and the associated storm surge. NHM with a horizontal scale of $10 \mathrm{~km}$ was used for the 21 member ensemble prediction. In addition to the initial perturbations, the effect of lateral boundary perturbations (LBPs) on tropical cyclone ensemble prediction was examined. When LBPs were implemented, the ensemble spread increased by $50 \%$, and root mean square errors (RMSEs) of the ensemble mean forecast became smaller than without LBPs.

A mesoscale singular vector (MSV) method was developed by Kunii (2010a). The tangent linear model and the adjoint model of NHM developed for JNoVA (Honda et al., 2005) were used in the Lanczos method with Gram-Schmidt re-orthogonalization to obtain the singular vector. Kunii (2010b) tested the MSV for a heavy rainfall event to assess MSV performance as the initial perturbation method. A torrential rainfall that occurred over central Japan on 29 August 2008 (Fig. 3a) was chosen. Ensemble forecast with a horizontal resolution of 15 $\mathrm{km}$ was conducted, where probabilistic values were determined by the proportion of members that predicted precipitation above a certain threshold. A greater-than- $30 \%$ probability of precipitation was estimated even with the large threshold of $50 \mathrm{~mm} / 3$ hours (Fig. 3c), whereas the control forecast (Fig. 3b) predicted rainfall of only about $20 \mathrm{~mm} / 3$ hours.
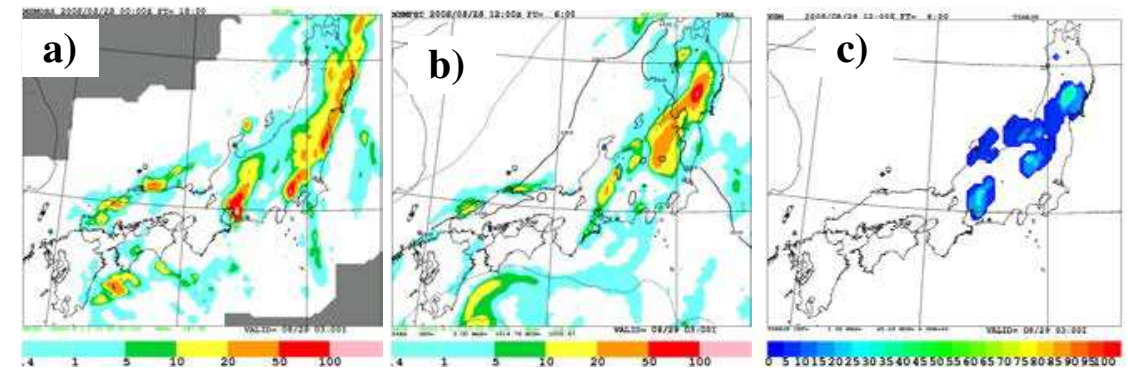

Fig. 4. a) 3-hour accumulated precipitation at 1800 UTC 28 August 2008 (Radar AMeDAS analyzed rainfall). b) Rainfall predicted by a control forecast $(\mathrm{FT}=06)$. c) Probability forecasts of 3-hour accumulated precipitation with a threshold of $50 \mathrm{~mm}$. After Kunii (2010b).

Kunii and Saito (2009) conducted a sensitivity analysis experiment using MSV to support the THORPEX Pacific Asian Regional Campaign (T-PARC). For TY0813 (SINLAKU), MSVs- 
based sensitivity areas for the typhoon were located on the right side of the moving direction of the typhoon, which was dominated by potential energy components in the midlower troposphere. Compared with global model singular vectors (GSVs), MSVs reflected small scale structures that affect mesoscale disturbances.

A mesoscale EPS system using MSV and GSV is under development at JMA (Ono et al., 2011), assuming operational application.

\subsubsection{WWRP Beijing Olympics 2008 RDP project}

An international research project of the World Weather Research Programme (WWRP), Beijing 2008 Olympics Research and Development Project (B08RDP; Duan et al. 2012) was conducted in conjunction with the Beijing 2008 Olympic Games. The main component of B08RDP was short-range forecasting of up to $36 \mathrm{~h}$ based on mesoscale EPSs with a horizontal resolution of $15 \mathrm{~km}$. Six institutions from five countries [MRI, NCEP, Meteorological Service of Canada (MSC), Central Institute for Meteorology and Geodynamics (ZAMG) of Austria, National Meteorological Center (NMC) of CMA, and Chinese Academy of Meteorological Sciences (CAMS)] participated in the project, and were requested to run their EPSs for a forecast time of up to $36 \mathrm{~h}$, starting every day at 1200 UTC.

Prior to the 2008 intercomparison period (one month, from 25 July to 23 August 2008), MRI developed five initial perturbation methods: (1) a downscaling of JMA's operational oneweek EPS (WEP; Saito et al., 2010a), (2) a targeted global model singular vector (GSV; Yamaguchi et al., 2009; Hara, 2010) method, (3) MSV method based on the adjoint model of NHM (Kunii, 2010a), (4) a mesoscale breeding of growing modes (MBD) method based on the NHM forecast (Saito, 2007), and (5) a local ensemble transform Kalman filter using NHM (LETKF; Miyoshi and Aranami, 2006; Seko, 2010). Saito et al. (2011a) objectively compared the results of the ensemble forecasts made with these five methods by evaluating the evolution of the ensemble spreads, the RMSE of the ensemble mean. GSV was selected as the initial perturbation method, considering its performance for weak to moderate rain QPF and the RMSE characteristics. The initial condition of the MRI/JMA system was prepared by applying Meso 4DVAR to the B08RDP area (Kunii et al., 2010a).

Kunii et al. (2011) reported the results of the international EPS intercomparison. Verification was performed using the MEP outputs interpolated into a common verification domain. For all systems, the ensemble spreads grew as the forecast time increased, and the ensemble mean improved the RMSEs compared with individual control forecasts in the verification against the analysis fields. MRI/JMA's EPS and the control run had the best performance among the six EPS systems for predicting surface conditions ( $2 \mathrm{~m}$ temperature and relative humidity) and weak to moderate rains, in terms of RSMEs against the initial condition and the threat scores.

Details of MRI and JMA's activities in B08FDP/RDP have been published as an MRI Technical Report (Saito et al., 2010b).

\subsubsection{Ensemble Kalman filter}

The ensemble Kalman filter (EnKF) technique is a new method of data assimilation that employs ensemble prediction to estimate forecast error. Miyoshi and Aranami (2006) 
applied four-dimensional expansion of LETKF to NHM and performed data assimilation experiments in a perfect model scenario with $5-\mathrm{km}$ grid spacing. The analysis equation for LETKF is:

$$
\mathbf{X}^{a}=\bar{x}^{f} e+\delta \mathbf{X}^{f} \tilde{\mathbf{P}}^{a}(\mathbf{H} \delta \mathbf{X})^{T} \mathbf{R}^{-1}\left(y^{o}-\overline{H\left(x^{f}\right)}\right) e+\delta \mathbf{X}^{f} \mathbf{T}
$$

Here, the overbar means the ensemble mean, and $\delta \mathbf{X}^{\mathrm{f}}$ the ensemble perturbation matrix. $\mathbf{H}$ is the tangent linear of the observation operator, and $e$ is an $m$-dimensional row vector. $\mathbf{P}^{\mathrm{a}}$ with tilde is the analysis error covariance matrix in the space spanned by forecast ensemble perturbations obtained by eigenvalue decomposition.

This system, NHM-LETKF, was modified by Seko (2010) and was tested as the initial perturbation generator for the mesoscale ensemble prediction in the B08RDP project.

Saito et al. (2012) examined the effects of LBPs on the MBD method and LETKF for mesoscale ensemble prediction. Introducing LBPs in the data assimilation cycles of LETKF improved the ensemble spread, the ensemble mean accuracy, and the performance of precipitation forecast. The accuracy of the LETKF analyses was compared with those of the Meso 4D-VAR analyses. With LBPs in the LETKF cycles, the RMSEs of the forecasts from the LETKF analyses improved, and some became comparable to those of the Meso 4D-VAR analyses.

Seko et al. (2011) performed data assimilation experiments with NHM-LETKF for an intense local rainfall event near the city of Kobe, western Japan, on 28 July 2008. They assimilated GEONET GPS TPWV data with conventional observation data. Adding GPS TPWV data tended to increase low-level water vapor and improve the precipitation forecast. The experiment with $5-\mathrm{km}$ resolution generated a rainfall band in western Japan that was not reproduced using conventional data alone. The experiment with $1.6-\mathrm{km}$ resolution effectively reproduced the observed band of intense rainfall.

\section{Ongoing plans}

\subsection{Next generation supercomputer project in Japan}

The next-generation supercomputer project, "Strategic Programs for Innovative Research (SPIRE)", is being carried out under a MEXT initiative. A supercomputer center was built in the city of Kobe by the RIKEN Advanced Institute for Computational Science (AICS). The supercomputer ' $\mathrm{K}$ ' achieved the benchmark performance of 10.51 petaflops in November 2011 with a total of 88,128 CPUs of the FUJITSU SAPARC64 processor.

The SPIRE project consists of five strategic research fields (life science and medicine, new material and energy, disaster prevention, engineering, and matter and universe). A five-year research plan of high performance NWP with cloud resolving ensemble data assimilation has been endorsed as a sub-subject of Field 3 in SPIRE (Saito et al., 2011c). The sub-subject on mesoscale NWP has three goals:

a. Development of a cloud resolving 4 dimensional data assimilation system,

b. Development and validation of a cloud resolving ensemble analysis forecast system, and

c. Basic research using very high resolution atmospheric models. 
The goal of a) is to dynamically predict local heavy rainfalls with deep convection by assimilating dense observation data. As described in the previous section, high resolution data assimilation methods (e.g., 4D-VAR and LETKF) have been developed and applied to case studies of cloud resolving forecast experiments of precipitation. In addition, a displaced ensemble variational assimilation method has also been developed and tested for a data assimilation experiment on satellite microwave imager data (Aonashi and Eito, 2011).

The goal of $b$ ) is to demonstrate the plausibility of the probabilistic quantitative forecast of heavy rainfalls for disaster prevention by cloud resolving ensemble NWP. A NHM-LETKF system using incremental approach has been developed by Fujita et al. (2011) and has been tested at MRI in anticipation of application to the K computer (Kuroda et al., 2011). A cloud resolving $(2 \mathrm{~km})$ ensemble forecast experiment was performed for the summer of 2010 as a test trial. The JNoVA 4DVAR analyses were used as the initial conditions, and the JMA oneweek ensemble prediction was used as the boundary perturbations. Duc et al. (2012) evaluated the ensemble prediction with the fraction skill score extended to temporal spaces. Results of the ensemble prediction will also be used for input data of river and flood models for risk management applications at Kyoto University.

In c), parameterizations in the cloud resolving model (e.g., the bulk cloud microphysics and the PBL scheme) are assesed and modified using the spectral BIN method and the LES model. Mechanisms of typhoons and tornados are also examined by very high resolution simulations.

\subsection{Tokyo metropolitan area convection study (TOMACS)}

Observation data are critical in high resolution data assimilation experiments. A field campaign in the Tokyo metropolitan area with a dense observation network is being conducted by MRI, the National Research Institute for Earth Science and Disaster Prevention (NIED), and twelve national institutions and universities in Japan. This field experiment is part of the research program 'Tokyo Metropolitan Area Convection Study for Extreme Weather Resilient Cities (TOMACS)'. The intensive operational periods are set in the summers of 2011 to 2013. The research project consists of the following three subjects.

1. Studies of extreme weather with dense meteorological observations.

2. Development of an extreme weather early detection and prediction system.

3. Social experiments on extreme weather resilient cities.

Unprecedented dense observations including fourteen Doppler radars, six Doppler lidars, a high resolution $(3 \mathrm{~km})$ AWS network, a KU-band fast scan MP radar, and five additional GPS stations are deployed as a possible international test-bed for deep convection (Fig. 5).

\subsection{Local forecast model at JMA}

JMA is planning to run a high resolution (2 $\mathrm{km}$ horizontally and 60 layers vertically) local forecast model in 2012 for the aviation weather forecast and the very short range forecast of precipitation. A rapid update cycle with a 3D-VAR version of JNoVA (Fukuda et al., 2011) will be used to prepare initial conditions hourly. Performance of NHM with a horizontal resolution of $2 \mathrm{~km}$ as a regional NWP model has been verified (Hirahara et al., 2011), while a new dynamical core 'asuca' is under development considering better computational efficiency in the new parallel computer system at JMA (Ishida et al. 2010). 


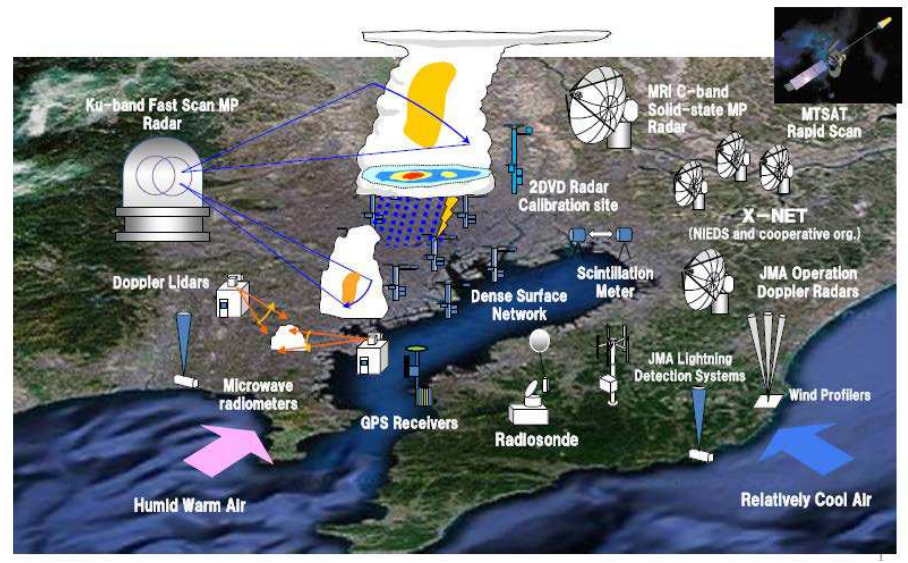

Fig. 5. Field campaign in TOMACS. Courtesy of NIED and the Meteorological Satellite and Observing System Research Department of MRI.

\section{Acknowledgments}

The author thanks T. Kato, C. Muroi, H. Eito, T. Hara, Y. Honda, Ts. Fujita, Ta. Fujita, J. Ishida and many scientists of NPD/JMA for their significant contributions towards developing NHM and its data assimilation systems. Figure 1 was quoted by courtesy of T. Hara and H. Kusabiraki of NPD. The author also thanks H. Seko, T. Kawabata, M. Kunii, Y. Shoji, S. Origuchi, K. Aonashi, T. Tsuyuki, Y. Yamada, M. Murakami, and several researchers of MRI, as well as T. Kuroda and L. Duc of JAMSTEC, for their research and development. Thanks are extended to T. Tokioka and F. Kimura of JAMSTEC and M. Maki of NIED for their leadership in conducting the research projects SPIRE and TOMACS. This study was partly supported by MEXT through a Grant-in-Aid for Scientific Research (21244074) "Study of advanced data assimilation and cloud resolving ensemble technique for prediction of local heavy rainfall".

\section{References}

Aonashi, K. and Eito, H. (2011). Displaced ensemble variational assimilation method to incorporate microwave imager data into a cloud-resolving model. J. Meteor. Soc. Japan, Vol.89, pp.175-194.

Aoyagi, T., and Seino, N. (2011). A square prism urban canopy scheme for the NHM and its evaluation on summer conditions in the Tokyo metropolitan area, Japan. J. Appl. Meteor. Climatol., Vol.50, pp.1476-1496.

Clark, T.L. (1977). A small scale numerical model using a terrain following coordinate system. J. Comp. Phys., Vol.24, pp.186-215.

Deardorff, J.W. (1980). Stratocumulus-capped mixed layers derived from a threedimensional model. Boundary-Layer Meteorol., Vol.18, pp.495-527.

Duan, Y., Gong, J., Du, J., Charron, M., Chen, J., Deng, G., DiMego, G., Hara, M., Kunii, M., Li, X., , Li, Y., Saito, K., Seko, H., Wang, Y., and Wittmann, C. (2012). An overview 
of Beijing 2008 Olympics Research and Development Project (B08RDP). Bull. Amer. Meteor. Soc., 381-403.

Duc, L., Saito, K. and Seko, H. (2012). Application of spatial-temporal fractions skill score to high-resolution ensemble forecast verification. Weather and Forecasting. (submitted)

Eito, H., Kato, T., Yoshizaki, M. and Adachi A. (2005). Numerical simulation of the quasistationary snowband observed over the southern coastal area of the Sea of Japan on 16 January 2001. J.Meteor.Soc.Japan, Vol. 83, pp. 551-576.

Eito, H., Murakami, M., Muroi, M., Kato, T., Hayashi, S. Kuroiwa, H., and Yoshizaki, M. (2010). The structure and formation mechanism of transversal cloud bands associated with the Japan-Sea polar-airmass convergence zone. J. Meteor. Soc. Japan, Vol.88, pp.625-648.

Fujibe, F., Saito, K., Wratt, D. S. and Bradley, S. G. (1999). A numerical study on the diurnal variation of low-level wind in the lee of a two-dimensional mountain. J. Meteor. Soc. Japan, Vol.77, pp.827-843.

Fujita, Ts. (2003). Higher order finite difference schemes for advection of NHM. Proceedings, CAS/JSC WGNE Res. Act. Atmos. Ocea. Model., Vol.33, pp.3.09-3.10.

Fujita, Ta., Kuroda, T. Seko, H. and Saito, K. (2011). Development of a meso ensemble data assimilation system. Presentation, 2011 Meeting on the Study of Advanced Data Assimilation and Cloud Resolving Ensemble Technique for Prediction of Local Heavy Rainfall.

Fukuda, J., Fujita, T., Ikuta, Y., Ishikawa, Y. and Yoshimoto, K. (2011). Development of JMA local analysis. CAS/JSC WGNE Res. Act. Atmos. Ocea. Model., Vol.41, pp.1.07-1.08.

Gal-Chen, T. \& Somerville, R. C. J. (1975). On the use of a coordinate transform for the solution of the Navier-Stokes equation. J. Comp. Phys., Vol.17, pp. 209-228.

Hara, T. (2007). Implementation of improved Mellor-Yamada Level 3 scheme and partial condensation scheme to JMANHM and their performance. CAS/JSC WGNE Res. Act. in Atmos. and Ocea. Modelling, 37, 0407-0408.

Hara, T., Aranami, K., Nagasawa, R., Narita, M., Segawa, T., Miura, D., Honda Y., Nakayama, H. and Takenouchi, K. (2007). Upgrade of the operational JMA nonhydrostatic mesoscale model. CAS/JSC WGNE Res. Act. Atmos. Ocea. Model., Vol.37, pp.5.11-5.12.

Hara, M. (2010). Global singular vector method. Tech. Rep. MRI. Vol.62, pp.61-72.

Hashimoto, A., Kato, T. Hayashi, S. and Murakami, M. (2008). Seedability assessment for winter orographic snow clouds over the Echigo Mountains. SOLA, Vol.4, pp.69-72.

Hayashi S., Aranami, K. and Saito, K. (2008). Statistical verification of short term NWP by NHM and WRF-ARW with $20 \mathrm{~km}$ horizontal resolution around Japan and Southeast Asia., SOLA, Vol.4, pp.133-136.

Hirahara, Y., Ishida, J. and Ishimizu, T. (2011). Trial operation of the Local Forecast Model at JMA. CAS/JSC WGNE Res. Act. Atmos. Ocea. Model., Vol.41, pp.5.11-5.12.

Honda, Y., Nishijima, M., Koizumi, K., Ohta, Y., Tamiya, K., Kawabata, T. and Tsuyuki, T. (2005). A pre-operational variational data assimilation system for a nonhydrostatic model at Japan Meteorological Agency: Formulation and preliminary results. Q. J. R. Meteorol. Soc., Vol.131, pp. 3465-3475.

Honda, Y., Y. and Sawada, K. (2008). A new 4D-Var for mesoscale analysis at the Japan Meteorological Agency. CAS/JSC WGNE Res. Act. Atmos. Ocea. Model., Vol.38, pp.01.7-01.8 
Ikawa, M. (1988). Comparison of some schemes for nonhydrostatic models with orography. J. Meteor. Soc. Japan, Vol.66, pp.753-776.

Ikawa, M., and Nagasawa, Y., (1989). A numerical study of a dynamically induced foehn observed in the Abashiri-Ohmu area. J. Meteor. Soc. Japan, Vol.67, pp.429-458.

Ikawa, M., and Saito, K. (1991). Description of a nonhydrostatic model developed at the Forecast Research Department of the MRI. Tech. Rep. MRI, Vol.28, 238pp.

Ikawa, M., Mizuno, H., Murakami, M., Yamada, Y. and Saito, K. (1991). Numerical modeling of the convective snow cloud over the Sea of Japan. --Precipitation mechanism and sensitivity to ice crystal nucleation rates--. J. Meteor. Soc. Japan, Vol.69, pp.641-667.

Ikuta, Y. and Honda, Y. (2011). Development of 1D+4DVAR data assimilation of radar reflectivity in JNoVA. CAS/JSC WGNE Res. Act. Atmos. Ocea. Model., Vol.41, pp. 1.09-1.10.

Iguchi, T., Nakajima, T., Khain, A. P., Saito, K., Takemura, T. and Suzuki, K. (2008). A study of the cloud microphysical properties in an East Asia region by a bin-type cloud model coupled with a meso-scale model. J. Geophys. Res., Vol.113, D14215, doi:10.1029/2007JD009774.

Iguchi, T., Nakajima, T., Khain, A. P., Saito, K., Takemura, Okamoto, H., Nishizawa, T. and Tao, W. (2012). Evaluation of cloud microphysics simulated using a meso-scale model coupled with bin and bulk microphysical schemes through comparison with data observed by cloud radars J. Atmos. Sci. (in press)

Ishida, J. (2007). Development of a hybrid terrain-following vertical coordinate for JMA nonhydrostatic model. CAS/JSC WGNE Res. Act. Atmos. Ocea. Model., Vol.37, pp.3.09-3.10.

Ishida, J., Muroi, C., Kawano, K., and Kitamura, Y. (2010). Development of a new nonhydrostatic model ASUCA at JMA. CAS/JSC WGNE Res. Act. Atmos. Ocea. Model. , Vol.40, pp.5.11-5.12.

Ishikawa, Y. (2010). Data assimilation of GPS precipitable water vapor into the JMA mesoscale numerical weather prediction model. CAS/JSC WGNE Res. Act. Atmos. Ocea. Model., Vol.40, pp.1.13-1.14.

Ishizaki, N and Takayabu, I. (2009). On the warming events over Toyama Plain by using NHRCM. SOLA, Vol.5: pp.129-132.

Kain, J. and Fritsch, J. (1993). Convective parameterization for mesoscale models: The KainFritsch scheme. The Representation of Cumulus Convection in Numerical Models, Meteor. Monogr., Vol.24, pp.165-170.

Kanada, S., Muroi, C., Wakazuki, Y., Yasunaga, K., Hashimoto, A., Kato, T., Kurihara, Yoshizaki M. and Noda, A. (2005). Structure of mesoscale convective systems during the late Baiu season in the global warming climate simulated by a nonhydrostatic regional model. SOLA, Vol.1, pp.117-120.

Kanada, S., S., Wada, A., Nakano M., and Kato, T. (2012). Effect of PBL schemes on the development of intense tropical cyclones using a cloud resolving model. J. Geophys. Res. (in press)

Kato, T., (1995). Box-Lagrangian rain-drop scheme. J. Meteor. Soc. Japan, Vol.73, pp. 241-245

Kato, T., and Saito, K. (1995). Hydrostatic and nonhydrostatic simulation of moist convection: Applicability of hydrostatic approximation to a high-resolution model. J. Meteor. Soc. Japan, Vol.73, pp.59-77.

Kato, T., (1998). Numerical simulation of the band-shaped torrential rain observed southern Kyushu, Japan on 1 August 1993. J. Meteor. Soc. Japan, Vol.76, pp. 97-128. 
Kawabata, T., Seko, H., Saito, K., Kuroda, T., Tamiya, K., Tsuyuki, T., Honda, Y. and Wakazuki, Y. (2007). An assimilation experiment of the Nerima heavy rainfall with a cloud-resolving nonhydrostatic 4-dimensional variational data assimilation system. J. Meteor. Soc. Japan, Vol.85, pp.255-276.

Kawabata, T., Kuroda, T., Seko, H. and Saito, K. (2011). A cloud-resolving 4D-Var assimilation experiment for a local heavy rainfall event in the Tokyo metropolitan area. Mon. Wea. Rev., Vol.139, pp.1911-1931.

Kawabata, T., Kunii, M., Bessho, K., Nakazawa, T., Kohno, N., Honda, Y. and Sawada, K. (2012). Reanalysis and reforecast of typhoon Vera (1959) using a mesoscale four dimensional variational assimilation system, J. Meteor. Soc. Japan, (submitted).

Keenan, T., Rutledge, S., Carbone, R., Wilson, J., Takahashi, T., May, P., Tapper, N., Platt, M., Hacker, J., Sekelsky, S., Moncrieff, M., Saito, K., Holland, G., Crook, A. and Gage, K. (2000). The Maritime Continent Thunderstorm Experiment (MCTEX): Overview and some results. Bull. Amer. Meteor. Soc., Vol.81, pp.2433-2455.

Koizumi, K., Ishikawa, Y. and Tsuyuki, T. (2005). Assimilation of precipitation data to JMA mesoscale model with a four-dimensional variational method and its impact on precipitation forecasts. SOLA, Vol.1, pp.45-48.

Kunii, M. and Saito, K. (2009). Sensitivity Analysis using the Mesoscale Singular Vector. CAS/JSC WGNE Res. Act. Atmos. Ocea. Model., Vol.39, pp.1.27-1.28.

Kunii, M., (2010a). MSV method. Tech. Rep. MRI, Vol.62, pp.73 - 77.

Kunii, M., (2010b). Heavy rainfall experiments using mesoscale SV. Tech. Rep. MRI, Vol.62, pp.73 - 77. pp.186-187.

Kunii, M., Saito, K. and Seko, H. (2010a). Mesoscale data assimilation experiment in the WWRP B08RDP. SOLA, Vol.6, pp.33-36.

Kunii, M., Shoji, Y., Ueno M. and Saito, K. (2010b). Mesoscale data assimilation of Myanmar cyclone Nargis. J. Meteor. Soc. Japan, Vol.88, pp.455-474.

Kunii, M., Saito, K., Seko, H., Hara, M., Hara, T., Yamaguchi, M., Gong, J., Charron, M., Du, J., Wang, Y. and Chen, D. (2011). Verifications and intercomparisons of mesoscale ensemble prediction systems in B08RDP. Tellus, Vol.63A, pp.531-549.

Kuroda, T., Saito, K., Kunii, M. and Kohno, N. (2010). Numerical simulations of Myanmar cyclone Nargis and the associated storm surge Part 1 : Forecast experiment with NHM and simulation of storm surge. J. Meteor. Soc. Japan, Vol.88, pp.521-545.

Kuroda, T., Fujita, Ta., Seko H. and Saito, K. (2011). Development and near future utilization of incremental LETKF data assimilation system at MRI. Presentation, 2011 Meeting on the Study of Advanced Data Assimilation and Cloud Resolving Ensemble Technique for Prediction of Local Heavy Rainfall.

Lin, Y.H., Farley, R.D. and Orville, H.D. (1983). Bulk parameterization of the snow field in a cloud model. J. Clim. Appl. Meteor., Vol.22, pp. 1065-1092.

Mashiko, W., Niino, H. and Kato, T. (2009). Numerical simulation of tornadogenesis in an outer-rainband minisupercell of typhoon Shanshan on 17 September 2006. Mon. Wea. Rev., 137, 4238-4260.

Miyoshi, T. and Aranami, K. (2006). Applying a four-dimensional local ensemble transform Kalman filter (4D-LETKF) to the JMA nonhydrostatic model (NHM). SOLA, Vol.2, pp.128 - 131.

Murata, A., Saito, K. and Ueno, M., (2003). The effects of precipitation schemes and horizontal resolution on the major rainband in typhoon Flo (1990) predicted by the MRI mesoscale nonhydrostatic model. Meteorol. Atmos. Phys., Vol. 82, pp. 55-73. 
Murata, A., (2009). A mechanism for heavy precipitation over the Kii peninsula accompanying typhoon Meari (2004). J. Meteor. Soc. Japan, Vol.87, pp.101-117.

Muroi, C., Saito, K., Kato, T. and Eito, H. (2000). Development of the MRI/NPD nonhydrostatic model. CAS/JSC WGNE Res. Act. Atmos. Ocea. Model., Vol.30, pp.5.25-5.26.

Nagasawa, R. T. Iwasaki, S. Asano, K. Saito and H. Okamoto, (2006). Resolution dependence of nonhydrostatic models in simulating the formation and evolution of low-level clouds during a "Yamase" event. J. Meteor. Soc. Japan, Vol.84, pp.969-987.

Nagata, M., Leslie, L., Kamahori, H., Nomura, R., Mino, H., Kurihara, Y., Rogers, E., Elsberry, R. L., Basu, B. K., Buzzi, A., Calvo, J., Desgagne, M., D’Isidoro, M., Hong, S.-Y., Katzfey, J., Majewski, D., Malguzzi, P., McGregor, J., Murata, A., Nachamkin, J., Roch, M. and Wilson, C. (2001). A mesoscale model intercomparison: A case of explosive development of a tropical cyclone (COMPARE III), J. Meteor. Soc. Japan, Vol.79, pp.999-1033.

Nakanishi, M. and Niino, H. (2004). An improved Mellor-Yamada level 3 model with condensation physics: Its design and verification. Bound.-Layer Meteor., Vol.112, pp.1-31.

Nakanishi, M., and Niino, H. (2006). An improved Mellor-Yamada level-3 model: Its numerical stability and application to a regional prediction of advection fog. Bound.-Layer Meteor., Vol.119, pp.397-407.

Ogura, Y. and Phillips, N.A. (1962). Scale analysis of deep and shallow water convection in the atmosphere. J. Atmos. Sci., Vol.19, pp.173-179.

Ohmori, S. and Yamada, Y. (2006). Development of cumulus parameterization scheme in the nonhydrostatic mesoscale model at the Japan Meteorological Agency. CAS/JSC WGNE Res. Act. Atmos. Ocea. Model. Vol.35, pp.4.21-4.22.

Ono, K., Honda, Y. and Kunii, M. (2011). A mesoscale ensemble prediction system using singular vector methods. CAS/JSC WGNE Res. Act. Atmos. Ocea. Model. Vol.40, pp.5.15-5.16.

Orlanski, I. (1976). A simple boundary condition for unbounded hyperbolic flows. J. Comp. Phys., Vol.21, pp.251-269.

Otsuka, S., and Yoden, S. (2011). Experimental development of a decision support system for prevention and mitigation of meteorological disasters based on ensemble NWP Data. Tech. Rep. MRI, Vol.65, pp.103-108.

Redelsperger, J.L., Brown, P., Guichard, F., Hoff, C., Kawasima, M., Lang, S., Montmerle, T., Nakamura, K., Saito, K., Seman, C. and Tao, W. K. (2000). A GCSS intercomparison of models for a tropical squall line observed during TOGA-COARE. Part 1: Cloudresolving models. Q. J. R. Met. Soc., Vol.126, pp.823-863.

Saito, K. and Ikawa, M. (1991). A numerical study of the local downslope wind "Yamajikaze" in Japan. J. Meteor. Soc. Japan, Vol. 69, pp.31-56.

Saito, K., (1993). A numerical study of the local downslope wind "Yamaji-kaze" in Japan. Part 2: Non-linear aspect of the 3-D flow over a mountain range with a col. J. Meteor. Soc. Japan, Vol.71, pp.247-271.

Saito, K., (1994). A numerical study of the local downslope wind "Yamaji-kaze" in Japan. Part 3: Numerical simulation of the 27 September 1991 windstorm with a nonhydrostatic multi-nested model. J. Meteor. Soc. Japan, Vol. 72, pp.301-329.

Saito, K., Thanh, L. and Takeda, T. (1994). Airflow over the Kii Peninsula and its relation to the orographic enhancement of rainfall. Pap. Met. Geophys., Vol.45, pp.65-90. 
Saito, K., Murakami, M., Matsuo, T. and Mizuno, H. (1996). Sensitivity experiments on the orographic snowfall over the mountainous region of northern Japan. J. Meteor. Soc. Japan, Vol.74, pp.797-813.

Saito, K., (1997). Semi-implicit fully compressible version of the MRI mesoscale nonhydrostatic model ---Forecast experiment of the 6 August 1993 Kagoshima torrential rain---. Geophys. Mag. Ser. 2, Vol.2, pp.109-137.

Saito, K., Doms, G., Schaetter, U. and Steppeler, J. (1998). 3-D mountain waves by the LokalModell of DWD and the MRI-mesoscale nonhydrostatic model. Pap. Met. Geophys., Vol. 49, pp.7-19.

Saito, K., (2001). Numerical simulation of clouds during the cold air outbreak. Parity, Vol.16, pp. 46-51. (in Japanese)

Saito, K., Kato, T., Eito H. and Muroi, C. (2001a). Documentation of the Meteorological Research Institute/Numerical Prediction Division unified nonhydrostatic model. Tech. Rep. MRI, Vol.42, 133pp.

Saito, K., Keenan, T., Holland, G. and Puri, K. (2001b). Numerical simulation of tropical diurnal thunderstorms over the Maritime Continent. Mon. Wea. Rev., Vol.129, pp.378-400.

Saito, K., (2003). Time-splitting of advection in the JMA Nonhydrostatic Model. CAS/JSC WGNE Res. Act. Atmos. Ocea. Model. Vol.33, pp.3.15-3.16.

Saito, K., (2004). Direct evaluation of the buoyancy and consideration of moisture diffusion in the continuity equation in the JMA nonhydrostatic model. CAS/JSC WGNE Res. Act. Atmos. Ocea. Model. Vol.34, pp.5.25-5.26.

Saito, K. and Ishida, J. (2005). Implementation of the targeted moisture diffusion to JMANHM. CAS/JSC WGNE Res. Act. Atmos. Ocea. Model. Vol.35, pp.5.17-5.18.

Saito, K., Fujita, Ta., Yamada, Y., Ishida, J., Kumagai, Y., Aranami, K., Ohmori, S., Nagasawa, R., Kumagai, S., Muroi, C., Kato, T., Eito H. and Yamazaki, Y. (2006). The operational JMA nonhydrostatic model. Mon. Wea. Rev., Vol.134, pp.1266-1298.

Saito, K., (2007). Development of a BGM method with the JMA nonhydrostatic mesoscale model. CAS/JSC WGNE Res. Act. Atmos. Ocea. Model. Vol.37, pp.5.27-5.28.

Saito, K., Ishida, J., Aranami, K., Hara, T., Segawa, T., Narita, M. and Honda, Y. (2007). Nonhydrostatic atmospheric models and operational development at JMA. J. Meteor. Soc. Japan, Vol.85B, pp.271-304.

Saito, K., Kuroda, T., Kunii, M. and Kohno, N. (2010a). Numerical Simulations of Myanmar Cyclone Nargis and the Associated Storm Surge Part 2: Ensemble prediction. J. Meteor. Soc. Japan. Vol.88, pp.547-570.

Saito, K., Kunii, M. Hara, M., Seko, H., Hara, T., Yamaguchi, M., Miyoshi, T. and Wong, W.K. (2010b). WWRP Beijing 2008 Olympics Forecast Demonstration / Research and Development Project (B08FDP/RDP). Tech. Rep. MRI, Vol.62, 214pp.

Saito, K., Hara, M., Kunii, M., Seko, H. and Yamaguchi, M. (2011a). Comparison of initial perturbation methods for the mesoscale ensemble prediction system of the Meteorological Research Institute for the WWRP Beijing 2008 Olympics Research and Development Project (B08RDP). Tellus, Vol.63A, pp.445-467.

Saito, K., Kuroda, T., Hayashi, S., Seko, H., Kunii, M., Shoji, Y., Ueno, M., Kawabata, T., Yoden, S. Otsuka, S., Trilaksono, N. J., Koh, T.Y., Koseki, S., Duc, L., Xin, X.K., Wong W.K. and Gouda, K.C. (2011b). International research for prevention and mitigation of meteorological disasters in Southeast Asia. Tech. Rep. MRI. Vol.65, 198 pp. 
Saito, K., H. Seko, T. Kuroda, T. Fujita, T. Kawabata, K. Aonashi, and T. Tsuyuki, (2011c). Next generation supercomputer project toward cloud resolving NWP. CAS/JSC WGNE Res. Act. Atmos. Ocea. Model., Vol.41, pp.5.19-5.20.

Saito, K., Seko, H.,Kunii M. and Miyoshi, T. (2012). Effect of lateral boundary perturbations on the breeding method and the local ensemble transform Kalman filter for mesoscale ensemble prediction. Tellus, Vol.64, doi: 10.3402/tellusa.v64i0.11594.

Sasaki, H., Kurihara, K. Takayabu, I. and Uchiyama, T. (2008). Preliminary experiments of reproducing the present climate using the non-hydrostatic regional climate model, SOLA, Vol.4, pp.25-28.

Sasaki, H., and Kurihara, K. (2008). Relationship between precipitation and elevation in the present climate reproduced by the non-hydrostatic regional climate model. SOLA, Vol.4, pp.109-112.

Satomura, T., Iwasaki, T., Saito, K., Muroi, C. and Tsuboki, K. (2003). Accuracy of terrain following coordinates over isolated mountain: Steep mountain Model intercomparison project (St-MIP). Annuals, Disas, Prev. Res. Inst., Kyoto University, Vol. 46, pp.337-346.

Sawada, M. and Iwasaki, T. (2007). Impacts of ice phase processes on tropical cyclone development. J. Meteor. Soc. Japan, Vol.85, pp.479-494.

Sawada, M., and Iwasaki, T. (2010). Impacts of Evaporation from Raindrops on Tropical Cyclones. Part I: Evolution and Axisymmetric Structure. J. Atmos. Sci., Vol.67, pp.71-83.

Seino, N., Sasaki, H., Sato, J., and Chiba, M. (2004). High-resolution simulation of volcanic sulphur dioxide dispersion over the Miyake Island. Atmospheric Environment, Vol.38, pp.7073-7081.

Seko, H., Hayashi, S., Kunii, M. and Saito, K. (2008). Structure of the regional heavy rainfall system that occurred in Mumbai, India, on 26 July 2005. SOLA, Vol.4, pp.129-132.

Seko, H., K. Saito, M. Kunii and M. Kyouda, (2009). Mesoscale ensemble experiments on potential parameters for tornado formation. SOLA, Vol.5, pp.57-60.

Seko, H., (2010). Local ensemble transform Kalman filter (LET) method. Tech. Rep. MRI, Vol.62, pp.80-84.

Seko, H., H., M. Kunii, Y. Shoji and K. Saito, (2010). Improvement of rainfall forecast by assimilations of ground-based GPS data and radio occultation data. SOLA. Vol.6, pp.81-84.

Seko, H., T. Miyoshi, Y. Shoji and K. Saito, (2011). A data assimilation experiment of PWV using the LETKF system -Intense rainfall event on 28 July 2008-. Tellus, Vol.63A, pp.402-414.

Seko, H., S. Hayashi and K. Saito, (2012). Generation mechanisms of convection cells near Sumatra Island in the Monsoon Season. Pap. Met. Geophys. (submitted)

Sherman, C.A., (1978). A mass-consistent model for wind fields over complex terrain. J. Appli. Meteor., Vol.17, pp. 312-319.

Shimbori, T., Aikawa, Y., Fukui, K., Hashimoto, A., Seino, N., and Yamasato, H. (2010). Quantitative tephra fall prediction with the JMA mesoscale tracer transport model for volcanic ash: A case study of the eruption at Asama volcano in 2009. Pap. Met. Geophys., Vol.61, pp.13-29. (in Japanese with English abstract and figure captions)

Shoji, Y. (2009). A study of near real-time water vapor analysis using a nationwide dense GPS network of Japan. J. Meteor. Soc. Japan, Vol.87, pp.1-18. 
Shoji, Y., Kunii, M. and Saito, K. (2009). Assimilation of nationwide and global GPS PWV data for a heavy rain event on 28 July 2008 in Hokuriku and Kinki, Japan. SOLA, Vol.5, pp.45-48.

Shoji, Y., Kunii, M. and Saito, K. (2011). Mesoscale Data Assimilation of Myanmar Cyclone Nargis. Part 2 : Assitilation of GPS derived Precipitable Water Vapor. J. Meteor. Soc. Japan, Vol.89, pp.67-88.

Smith, R. B., (1980). Linear theory of stratified hydrostatic flow past an isolated mountain. Tellus, Vol. 32, pp. 348-364.

Takano, I., Aikawa, Y. and Gotoh, S. (2007). Improvement of photochemical oxidant information by applying transport model to oxidant forecast, CAS/JSC WGNE Res. Act. Atmos. Ocea. Model., Vol.37, pp.5.35-5.36.

Tapp, M. C. \& White, P. W., (1976). A non-hydrostatic mesoscale model. Q. J. R. Meteorol. Soc., Vol.102, pp. 277-296.

Trilaksono, N. J., Otsuka, S., Yoden, S., Saito, K. and Hayashi, S. (2011). Dependence of model simulated heavy rainfall on the horizontal resolution during the Jakarta flood event in January-February 2007. SOLA, Vol.7, pp.193-196.

Trilaksono, N. J., Otsuka, S. and Yoden, S. (2012). A time-lagged ensemble simulation on the modulation of precipitation over West Java in January-February 2007. Mon. Wea. Rev., Vol.140. 601-606.

Wada, A. (2009). Idealized numerical experiments associated with the intensity and rapid intensification of stationary tropical cyclone-like vortex and its relation to initial sea-surface temperature and vortex-induced sea-surface cooling. Journal of Geophysical Research, Vol.114, doi:10.1029/2009JD011993.

Wada, A., Kohno, N. and Kawai, Y. (2010). Impact of wave-ocean interaction on typhoon Hai-Tang in 2005. SOLA, Vol.6A, pp.13-16.

Wada, A., (2012). Numerical study on the effect of the ocean on tropical-cyclone intensity and structural change. InTech, (this volume).

Wong, W.K., Sumdin, S. and Lai, S.T. (2010). Development of Air-Sea Bulk Transfer Coefficients and Roughness Lengths in JMA Non-hydrostatic Model and Application in Prediction of an Intense Tropical Cyclone. SOLA, Vol. 6, pp.65-68.

Yamada, Y., (2003). Introduction to the Kain-Fritsch scheme. Separate volume of annual report of NPD, Vol.49, pp.84-89. (in Japanese)

Yamaguchi, M., Sakai, R., Kyoda, M., Komori, T. and Kadowaki, T. (2009). Typhoon ensemble prediction system developed at the Japan Meteorological Agency. Mon. Wea. Rev. Vol.137, pp.2592 - 2604.

Yanase, W., Niino, H., and Saito, K. (2002). High-resolution numerical simulation of a polar low. Geophys. Res. Lett. , Vol.29, 1658, doi:10.1029/2002GL014736.

Yanase, W., G. Fu, H. Niino, and T. Kato, (2004). A polar low over the Japan Sea on 21 January 1997. Part II: A numerical study. Mon. Wea. Rev., Vol.132, pp. 1552-1574.

Yanase, W., and Niino, H., (2007). Dependence of polar low development on baroclinicity and physical processes: an idealized high-resolution numerical experiment. $J$. Atmos. Sci., Vol.64, pp.3044-3067.

Yasunaga, K., Sasaki, H., Wakazuki, Y., Kato, T., Muroi, C., Hashimoto, A., Kanada, S., Kurihara, K., Yoshizaki M. and Sato, Y. (2005). Performance of the long-term integrations of the Japan Meteorological Agency nonhydrostatic model with use of the spectral boundary coupling method. Weather and Forecasting, Vol.20, pp.10611072 . 


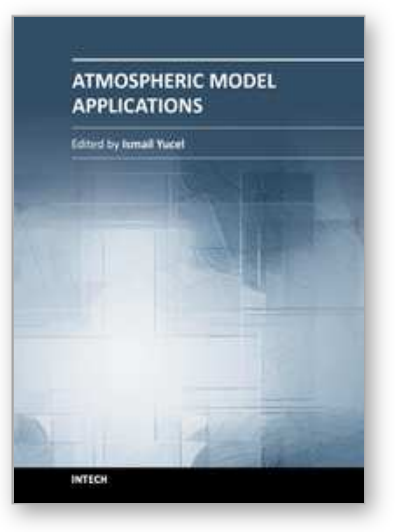

\author{
Atmospheric Model Applications \\ Edited by Dr. Ismail Yucel
}

ISBN 978-953-51-0488-9

Hard cover, 296 pages

Publisher InTech

Published online 04, April, 2012

Published in print edition April, 2012

This book covers comprehensive text and reference work on atmospheric models for methods of numerical modeling and important related areas of data assimilation and predictability. It incorporates various aspects of environmental computer modeling including an historical overview of the subject, approximations to land surface and atmospheric physics and dynamics, radiative transfer and applications in satellite remote sensing, and data assimilation. With individual chapters authored by eminent professionals in their respective topics, Advanced Topics in application of atmospheric models try to provide in-depth guidance on some of the key applied in atmospheric models for scientists and modelers.

\title{
How to reference
}

In order to correctly reference this scholarly work, feel free to copy and paste the following:

Kazuo Saito (2012). The JMA Nonhydrostatic Model and Its Applications to Operation and Research, Atmospheric Model Applications, Dr. Ismail Yucel (Ed.), ISBN: 978-953-51-0488-9, InTech, Available from: http://www.intechopen.com/books/atmospheric-model-applications/the-jma-nonhydrostatic-model-and-itsapplications-to-operation-and-research

\section{INTECH}

open science | open minds

\section{InTech Europe}

University Campus STeP Ri

Slavka Krautzeka 83/A

51000 Rijeka, Croatia

Phone: +385 (51) 770447

Fax: +385 (51) 686166

www.intechopen.com

\section{InTech China}

Unit 405, Office Block, Hotel Equatorial Shanghai

No.65, Yan An Road (West), Shanghai, 200040, China

中国上海市延安西路65号上海国际贵都大饭店办公楼 405 单元

Phone: +86-21-62489820

Fax: $+86-21-62489821$ 
(C) 2012 The Author(s). Licensee IntechOpen. This is an open access article distributed under the terms of the Creative Commons Attribution 3.0 License, which permits unrestricted use, distribution, and reproduction in any medium, provided the original work is properly cited. 